\title{
Radiation-induced easy peeling and oblong fruit mutants of the tomato $^{1}$
}

\author{
K. Verkerk and R. B. Contant
}

Department of Horticulture, Agricultural University, Wageningen, the Netherlands Institute for Atomic Sciences in Agriculture, Wageningen, the Netherlands

Received 30 December 1968

\section{Summary}

The genetics of two radiation-induced mutants of the tomato variety Moneymaker, 'easy peeling' and 'oblong fruit with strong skin', were studied. Both were governed by a single recessive gene. The combination of both traits was achieved by crossing. It was impossible to break the association between oblong fruit and strong skin, so that round easy peeling fruit could not be combined with strong skin. Hybrid easy peeling material with round or oblong fruit shape was subjected to selection for yield. Improvements up to $30 \%$ over Moneymaker were reached under experimental conditions; selected lines have been issued to breeders. The easy peeling trait may be of interest both for the canning industry and for fresh consumption.

\section{Introduction}

In the course of investigations on the mutagenic effectiveness of thermal neutrons and X-rays on tomato seeds, two mutants were found having fruit characteristics considered to be of potential practical interest. Their genetics and certain of their phenotypic, agronomic and technological features were studied.

\section{Materials, aims and methods}

\section{Mutants}

One mutation, discovered in the variety Moneymaker following seed irradiation with a low dose of thermal neutrons, conferred remarkably easy peeling of the ripe fruit without immersion in hot water. Except for a weaker growth, general appearance of the mutant line was as in Moneymaker. It had a somewhat greater tendency to fruit cracking, especially when fruits were picked red-ripe.

The other mutation, governing an oblong fruit shape, was found amongst the progeny of a plant grown from seed exposed to $80 \mathrm{krad}$ of $\mathrm{X}$-rays. The oblong fruit shape was combined with a remarkably strong skin rendering the unpeeled fruit unpalatable.

I Publication 326, Laboratorium voor Tuinbouwplantenteelt, Landbouwhogeschool, Wageningen, the Netherlands. 


\section{Aims}

In view of the potential importance of both mutants it was decided to study their genetic nature; to this end both mutant lines were crossed. Furthermore, two practical aims were pursued by means of selection in $F_{2}$ and subsequent generations. Firstly the incorporation of a strong skin into round fruited easy peeling tomatoes in order to render these resistant to skin cracking, notably for home consumption and for the catering business. Secondly the introduction of the easy peeling trait into the oblong fruited type to serve the industry of canned whole fruit, the so-called 'pelati'. The first objective would require the dissociation of the high skin strengh from the oblong fruit shape. The quality characteristics of Moneymaker would have to be maintained. Selection for yield was an obvious additional requirement as both mutant lines produced 10-30\% less than Moneymaker, depending upon growth conditions, locality and season.

\section{Selection}

Five round fruited individuals containing the easy peeling character were selected in 1966 from the $F_{2}$ of the reciprocal hybrids. In spring and summer of 1967 , the progenies of these five selections $\left(\mathrm{F}_{3}\right)$ were tested against the easy peeling mutant line and Moneymaker, in an $8 \times 8$ Latin square containing 4 plants per object per replication. Observations were made on date of flowering, fruit shape, fruit yield and plant height till the fifth cluster.

All $F_{3}$ lines segregated for fruit shape. From the highest yielding line, the best 6 round fruited and 4 oblong fruited individuals were retained. Their selfed offspring $\left(\mathrm{F}_{4}\right)$ was grown in spring/summer 1968, together with both original mutant lines and Moneymaker, all represented by one row of 9 plants. The plants were topped at a height of $2 \mathrm{~m}$. Mean weight per fruit was determined from a random sample of 30 ripe fruits per object picked in the second week of harvesting. Total yield was estimated by multiplying this mean weight by the total number of good fruits developing on the first five clusters. Additional observations were made on height of the fifth cluster and on total fresh weight of the main stem from ground level up to the fifth cluster; the latter information, converted to average weight per $1 \mathrm{~cm}$ stem piece, was considered to represent a useful quantitative criterium of sturdiness. Skin strength was measured with an 'Instron' apparatus, using $10 \times 30 \mathrm{~mm}$ pieces of skin, carefully removed from ripe undamaged fruit. In addition, skin thickness was measured on skin specimens dried at room temperature. These objective measurements were correlated with macroscopic determinations on site, i.e. in the greenhouse.

\section{Results}

\section{Easy peeling mutant}

No anatomical differences were found between the pericarp of the easy peeling mutant and its mother variety Moneymaker. The first tests on enzyme activity at different depths of the fruit wall indicated that cellulase and pectinase activity of the outer $2 \mathrm{~mm}$ of the fruit wall were much higher in the mutant, which would allow an easy explanation of the mutant character (Verkerk et al., 1967). However, these findings could not be confirmed in subsequent very detailed analyses, nor could differences in ease of peeling be attributed to cellulase inhibitors (Verkerk and Contant, 1968). It must therefore be concluded that the mechanism of easy skin detachment 
without adhering flesh and without the use of hot water treatment, is still unknown. It was found that pressure on the red-ripe fruit will cause slightly bruised patches, resulting from the destruction of cells immediately below the skin. Furthermore, skin cracking of fully ripe fruit was found to be more common than in Moneymaker, especially under growth conditions inductive to the formation of very large fruit; when the fruits were picked at the correct orange-red stage, this defect was avoided. Examination of easy peeling material in which the factor for oblong fruit had been introduced, denonstrated that the tendency to bruising remained but that the susceptibility to skin cracking could be overcome.

Easy peeling individuals could be identified by counting the number of skin fragments from fruits of comparable degree of ripening, when peeled with a standard

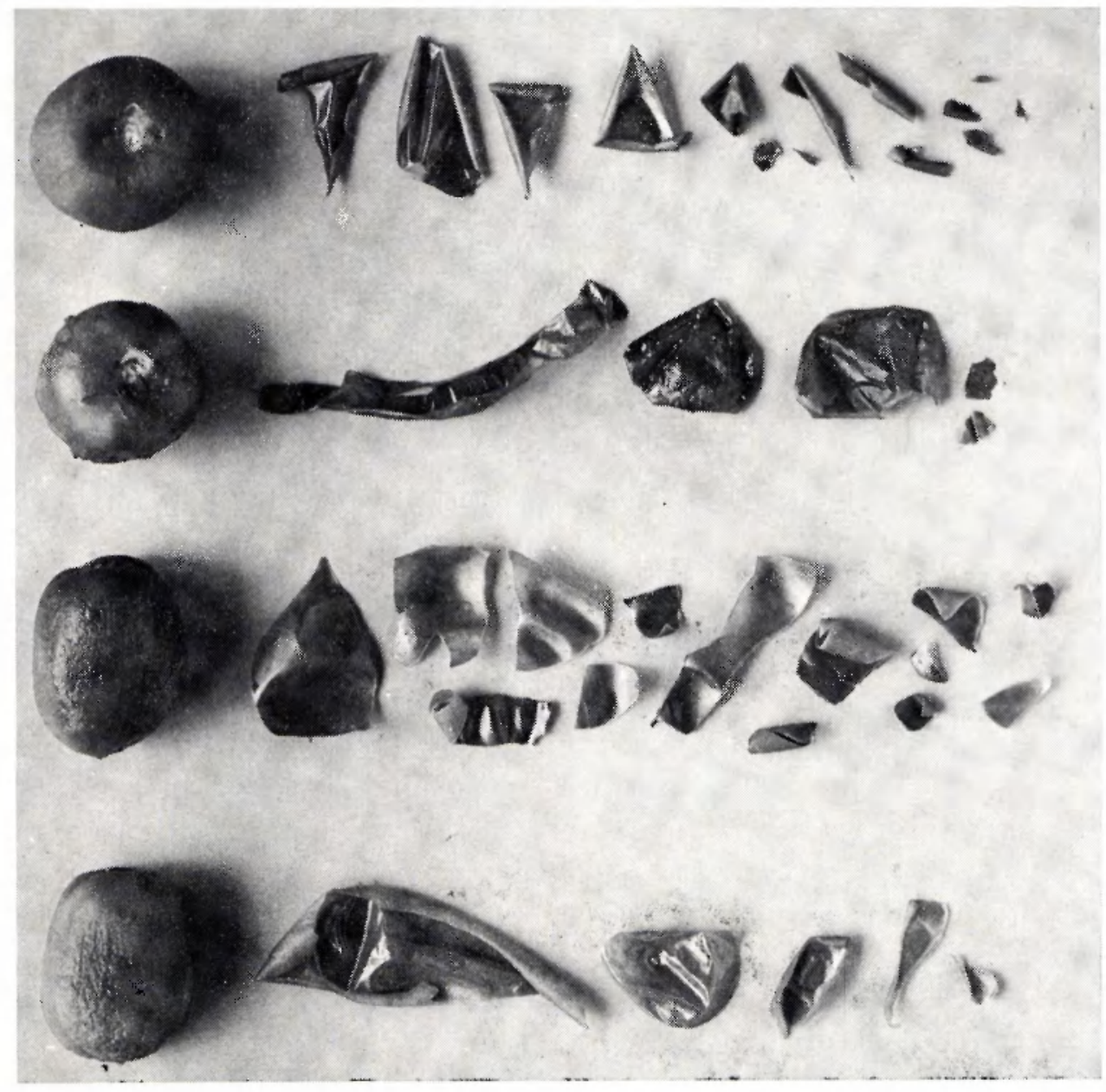

Fig. I From top to bottom: fruit shape and skin fragments of Moneymaker, the 'easy peeling' mutant, the 'oblong fruit' mutant and an oblong fruited easy peeling selection. 
type of knife at room temperature. The result was greatly influenced by the degree of ripening but not by fruit size. Though the number of skin fragments was rather variable, even between fruits from the same plant, identification of the easy peeling individuals was easy as their fruits were on average peeled in 4 pieces against 18 for Moneymaker or any of the other genotypes (Fig. 1); no intermediate types were found in hybrid material, indicating the absence of modifying factors. The easy peeling trait was manifest under widely varying growth conditions, from outdoor culture in Italy to early season cultivation in heated greenhouses in the Netherlands.

\section{Oblong fruit mutant}

The oblong fruit mutant possessed a markedly stronger fruit skin than Moneymaker; the force needed to tear skin specimens off the former was about twice as large as that needed for Moneymaker, $1256 \pm 121 \mathrm{~g}$ against $600 \pm 41 \mathrm{~g}$; in spite of considerable variation within each group, the two classes of skin strength were easily distinguished and there was no evidence of intermediate types.

Skin thickness measurements yielded, for the mutant and Moneymaker respectively, values of $83 \pm 4.4$ and $35 \pm 2.3 \mu \mathrm{m}$. From these data it was concluded that the greater skin strength of the oblong fruit mutant was essentially due to its greater skin thickness and not to a greater strength of the cell walls. The twofold difference between the two categories allowed routine macroscopic determinations, thus enabling the screening of large plant populations on site. This is particularly useful with a view to detecting the desired combination of round fruit with strong skin in easy peeling material derived from the cross of the two mutant lines.

In addition to the previous character, the mutant appeared to have considerably greater vigour, producing taller plants with longer internodes; consequently, less inflorescences had been formed at a given height, while e.g. the fifth cluster occurred at about 1.4 times the height in Moneymaker. Another distinct feature of this mutant is its somewhat drooping foliage. An important disadvantage appeared to be its susceptibility to blossom-end rot, at least under the rather high temperatures prevailing in the present experiments.

\section{$F_{1}$ analysis}

Examination of the $F_{1}$ 's in 1966 and 1967 showed that reciprocal differences were absent and that the hybrid closely resembled the mother variety with regard to peeling properties, fruit shape and skin thickness. Thus, 'easy peeling', 'oblong fruit' and 'strong skin' appeared to be inherited as recessive factors, while plasmatic modifying factors were not involved. Results also suggested recessive or intermediary inheritance of the tall plant characteristic occurring in association with 'oblong fruit'.

\section{$F_{2}$ analysis}

The genetics of the various traits was further studied by $F_{2}$ analysis. The numbers of plants with easy versus normal peeling, with oblong versus normal round fruit, and with both traits in the four possible combinations, were tested by means of the $\mathrm{Chi}^{2}$ test against the numbers expected on the basis of a $1: 3$ ratio. No significant departure from homogeneity was found for either character, so that one may conclude that 'easy peeling' and 'oblong fruit' are each based on one single recessive gene or point mutation, to which the symbols $e p$ for 'easy peeling' and $o b l$ for 'oblong' were assigned (Verkerk and Contant, 1967). There was no evidence of genetic linkage between these factors nor of the existence of plasmatic modifying factors. 
In the $F_{2}$, all 72 segregants with oblong fruit were found to possess a strong fruit skin, whereas all 232 round fruited plants had the normal skin strength of Moneymaker; no intermediate skin strengths were detected. Thus, there is yet no evidence on the possibility to dissociate 'oblong fruit' from 'strong skin'. The present results indicate that if these features are not in fact pleiotropic effects of the same gene, there must at least be very close linkage.

Mean plant height till the fifth cluster was $128.5 \pm 1.2 \mathrm{~cm}$ in the round fruited $\mathrm{F}_{2}$ plants, against $150.6 \pm 2.5 \mathrm{~cm}$ in the plants with oblong fruit. This confirms the close association between the factors for internode length and fruit shape.

The tendency towards a higher incidence of blossom-end rot in the 'oblong fruit' mutant was also found in hybrid segregants with the same fruit shape; thus this susceptibility was not enhanced by the presence of the 'easy peeling' trait.

\section{Selection}

Five $F_{2}$ plants were selected for round fruit, easy peeling and good yield; one of these was described as a 'very good' yielder. All five plants were vigorous and one was of the very tall type characteristic of the oblong fruit mutant. Their progenies, grown in 1967, segregated for fruit shape, showing that all had been heterozygous for the $o b l$ gene. The five $\mathrm{F}_{3}$ lines differed considerably from their mother variety in respect of plant height till the fifth cluster: $112 \mathrm{~cm}$ for Moneymaker, $125 \mathrm{~cm}$ for the original easy peeling mutant line, $142-147 \mathrm{~cm}$ for four of the selected lines and $166 \mathrm{~cm}$ for the fifth line; the latter was the offspring of the exceptionally tall $F_{2}$ plant. As in the $F_{2}$, the $F_{3}$ plants with oblong fruits were on average significantly taller than the round fruited segregants, $158.0 \pm 3.0$ versus $143.6 \pm 1.6 \mathrm{~cm}$ up to the fifth cluster. However, the large variation within each group caused considerable overlapping of the frequency distributions.

In respect of total fruit yield from five clusters, Moneymaker came first while the 'easy peeling' mutant was one but lowest. The lowest yielding $F_{3}$ was that derived from the very tall selection; it had the lowest number of fruits combined with the highest average fruit weight. The other four lines did not differ significantly from Moneymaker but it should be noted that the best of these four was the offspring of the $F_{2}$ plant of which the yield had been described as 'very good' (Contant and Verkerk, 1968).

From this last $\mathrm{F}_{3}$ line, which on average differed from Moneymaker by only $5 \%$, new selections were made: the 6 highest yielding round fruited plants and the 4 highest yielding oblong fruited plants $(e p o b l)$; the relevant information on these 10 plants is given in Table 1.

Table 1 also contains the summarized results of the $\mathbf{F}_{4}$ test, carried out in 1968 on 9 plants per line. Three out of the six round fruited $F_{3}$ selections appeared to segregate for fruit shape while the other three were true breeding. Plant height was rather variable; the rank correlation between the $F_{3}$ plants and the mean of their $F_{4}$ offspring was insignificant. However, within each group, consisting of the numbers $1-3,4-6$ and $7-10$, the order of the plant heights was virtually the same in $F_{3}$ and $F_{4}$. Considering that the $F_{3}$ estimates were based on one plant only whereas the $\mathrm{F}_{4}$ was grown one year later, this result indicates a fair heritability of plant height. There was wide variation in plant height till the fifth cluster between the ten $F_{3}$ plants which were all derived from one $F_{2}$ plant. The $F_{4}$ showed a high within-line variability of the selections compared with the variety Moneymaker. These facts suggest that this character plant height is determined by several genes which 
Table 1 Data on ten $F_{3}$ individuals derived from a single $F_{2}(\mathrm{ep} \times$ obl) plant and on their progenies, in comparison with controls

\begin{tabular}{|c|c|c|c|c|c|c|c|}
\hline \multirow{2}{*}{$\begin{array}{l}\text { Identity } \\
\text { of plant } \\
\text { or line }\end{array}$} & \multicolumn{3}{|c|}{$\begin{array}{l}F_{3} \text { single plants } \\
\text { selected in } 1967\end{array}$} & \multicolumn{4}{|c|}{$\begin{array}{c}F_{4} \text { progeny of selected } F_{3} \text { plants } \\
\text { grown in } 1958^{2}\end{array}$} \\
\hline & $\begin{array}{l}\text { Fruit } \\
\text { shape }\end{array}$ & $\begin{array}{c}\text { Plant } \\
\text { height } \\
\text { till 5th } \\
\text { cluster } \\
(\mathrm{cm})\end{array}$ & $\begin{array}{c}\text { Fruit } \\
\text { yield } \\
(\times 10 \mathrm{~g})\end{array}$ & $\begin{array}{l}\text { Segregation } \\
\text { (round : } \\
\text { oblong) }\end{array}$ & $\begin{array}{c}\text { Plant height } \\
\text { till } 5 \text { th } \\
\text { cluster } \\
\text { (cm) }\end{array}$ & $\begin{array}{c}\text { Fruit } \\
\text { yield } \\
(\times \quad 10 \mathrm{~g})\end{array}$ & $\begin{array}{l}\text { Mean weight } \\
\text { of } 1 \mathrm{~cm} \text { stem } \\
(\times 10 \mathrm{mg})\end{array}$ \\
\hline 1 & round & 114 & 448 & $9: 0$ & $120 \pm 4.0$ & 448 & 202 \\
\hline 2 & round & 136 & 342 & $9: 0$ & $134 \pm 2.2$ & 322 & 171 \\
\hline 3 & round & 168 & 370 & $9: 0$ & $154 \pm 4.0$ & 343 & 219 \\
\hline 4 & round & 124 & 338 & $7: 2$ & $129 \pm 4.9$ & 320 & 182 \\
\hline 5 & round & 137 & 388 & $7: 2$ & $142 \pm 7.6$ & 351 & 187 \\
\hline 6 & round & 140 & 333 & $6: 3$ & $153 \pm 8.5$ & 350 & 174 \\
\hline 7 & oblong & 122 & 405 & $0: 9$ & $150 \pm 3.8$ & 346 & 164 \\
\hline 8 & oblong & 147 & 345 & $0: 9$ & $158 \pm 5.1$ & 368 & 161 \\
\hline 9 & oblong & 155 & 285 & $0: 9$ & $162 \pm 4.8$ & 356 & 164 \\
\hline 10 & oblong & 145 & 388 & $0: 9$ & $166 \pm 6.6$ & 401 & 178 \\
\hline Mean of & & & & & & & \\
\hline 1 to 10 & 一 & 139 & 364 & - & 147 & 360 & 180 \\
\hline Moneymaker ${ }^{1}$ & round & 112 & 333 & $9: 0$ & $104 \pm 1.9$ & 335 & 138 \\
\hline$e p$ mutant 1 & round & 125 & 281 & $9: 0$ & $133 \pm 8.2$ & 310 & 150 \\
\hline$o b l$ mutant & oblong & - & - & $0: 9$ & $164 \pm 7.0$ & 291 & 149 \\
\hline
\end{tabular}

1 Mean of 32 plants per line or variety in 1967

2 Mean of 9 plants per line or variety

must have mutated simultaneously with the $o b l$ factor; the association between fruit shape and plant height which was observed in the $F_{2}$ and $F_{3}$ populations, suggests genetic linkage between these factors for plant height and the obl gene.

Table 1 shows that in $F_{4}$ the selections with oblong fruit were again on average taller than those having round fruit. Moneymaker was shortest in both years.

The ten selected $\mathrm{F}_{3}$ individuals produced on average $9 \%$ more than the variety Moneymaker; the corresponding $90 \mathrm{~F}_{4}$ plants produced $7 \%$ more than Moneymaker. There was only a slight and insignificant correlation $(r=0.63)$ between the yield of the single plants in 1967 and that of their selfed offspring in 1968. However, the best yielding $F_{3}$ plant, No 1 , also gave the highest yielding $F_{4}$, outyielding Moneymaker by $30 \%$; in both generations this line was the shortest of all, though still being slightly taller than Moneymaker. On the other hand the second best yielder, No 10, was in the $F_{4}$ the tallest of all selections, strongly suggesting an absence of correlation between yielding potential and plant height till the fifth cluster.

Fruit yield per plant of Moneymaker was virtually the same in 1967 and 1968. This was also true for the mean of all 10 selections and their selfed progenies, though not for each selection separately, except for the best yielders, Nos 1 and 10 .

\section{Discussion}

Although the factors responsible for the mutant characteristics behave as single genes, the possibility that they are small structural aberrations, e.g. deletions, involving 
possibly more than one gene, can of course not be excluded. The factors for 'easy peeling' and 'oblong fruit' clearly behave as single recessive genes in independent positions. They received the symbols $e p$ and $o b l$ respectively.

One of the main defects associated with the $e p$ gene is the tendency to skin cracking under certain growth conditions. In combination with $o b l$ this difficulty does not arise, which suggests that one should aim at combining the ep gene with a factor governing a stronger fruit skin. In the present studies a search was made for recombinants possessing the skin strength of the oblong fruit mutant, but not its fruit shape. So far, these attempts have failed. An alternative would be the crossing with other strong-skin varieties to overcome the weakness of skin inherent in Moneymaker and its $e p$ mutant. Finally, one might try to induce a mutation for stronger skin into the round fruited $e p$ selections by means of irradiation, or to dissociate 'oblong fruit' from 'strong skin' by radiation on the assumption that the two traits are not truly pleiotropic effects. The chief disadvantage of the obl mutant and its oblong fruited hybrid derivatives is their susceptibility to blossom-end rot. This susceptibility, mainly apparent under high temperature conditions in the greenhouse, was not enhanced by the ep gene. A major asset on the other hand is their strong skin, conferring complete absence of skin cracking even in combination with ep. The tendency of bruising of the easy peeling mutant could, however, not be eliminated by crossing with $o b l$; this feature is probably directly associated with the easy peeling trait and may be difficult or impossible to remove.

The $o b l$ mutant possessed longer internodes than Moneymaker or the $e p$ mutant. In the $\mathrm{F}_{2}$ of the hybrid between $o b l$ and $e p$, the oblong fruited plants had on average much longer internodes than the round fruited individuals. The same was true in the offspring of selected $F_{2}$ plants heterozygous for fruit shape, though the differences were less and the frequency distributions showed considerable overlapping. The segregation for plant height amongst the progeny of a single $F_{2}$ plant (Table 1) demonstrates that several factors governing this character must have mutated simultaneously with the obl factor and the observed association with the latter suggests that at least some of these factors are situated on the same chromosome and probably close to the $o b l$ locus. This situation, if correctly interpreted, may represent an example of simultaneous mutation of 'clusters' of genes.

During these studies it has become clear that it will be very difficult to produce an easy peeling tomato variety that would be equally suitable for peeled and unpeeled fresh consumption, the main reason being that the skin of an unpeeled easy peeling fruit becomes detached in large unpalatable pieces.

The best round and oblong fruited ep selections have been issued to breeders. It should be possible to incorporate this gene into any variety without appreciably altering its quality characteristics.

\section{Acknowledgments}

The assistance of W. F. S. Duffhues and C. P. de Jager is gratefully acknowledged. The work was carried out at the Department of Horticulture, Agricultural University, Wageningen, under a sub-contract and in collaboration with the Association EURATOM - Institute for Atomic Sciences in Agriculture, Wageningen. 


\section{References}

Contant, R. B. and Verkerk, K., 1968. Selection of high yielding easy peeling tomato lines for fresh consumption and canning. Rep. Tomato Genet. Cooperative 18: 11-12.

Verkerk, K. and Contant, R. B., 1967. Genetic analysis of two Moneymaker mutants. Rep. Tomato Genet. Cooperative 17: 56-58.

Verkerk, K. and Contant, R. B., 1968. Further studies on the genetics of $o b l$ and $e p$ and associated characters. Rep. Tomato Genet. Cooperative 18: 43-44.

Verkerk, K., Contant, R. B., Rombouts, F. M. and Berkholst, C. E. M., 1967. Easy peeling neutronic mutant of tomato. Rep. Tomato Genet. Cooperative 17: 58-59. 